Linguistics and Literature Journal
Vol. 1, No. 2, 62-69
E-ISSN: 2723-7273

\title{
A METAPRAGMATIC ANALYSIS: A STUDY OF PRAGMATIC FAILURE FOUND IN INDONESIAN EFL STUDENTS
}

\author{
Merawati Hutauruk ${ }^{1}$, Dian Puspita ${ }^{2}$ \\ Universitas Teknokrat Indonesia ${ }^{1,2}$ \\ hutauruk.merawati@gmail.com¹, dian.puspita@teknokrat.ac.id ${ }^{2}$
}

\begin{abstract}
Received: (October, 2020)
Accepted: (November, 2020)

Abstract

This research aimed to investigate the possibilities of pragmatic failure done by Indonesian EFL students through their translation. This study employed theories by Thomas (1983) and Muir et al (2011) to answer the research question coming along with the problem concerned. As mentioned by Natrio (2018) that Indonesian EFL students lack pragmatic competence because they don't recognize the intention of one language transferring is inappropriate. This research used a descriptive qualitative method in collecting the data. The data were coming from students ${ }^{\text {ee }}$ performance in translating short dialogue texts which contained idioms in them. The instrument given was two-way translation, English-Indonesian, and vice versa. As the result, this study found that the respondents experienced pragmatic failure in their performance which happened in several types, namely pragma-linguistic failure and socio-pragmatic failure, both of which were found in all types of texts given. It was also found that the failure that happened in English-Indonesian text was higher in number compared to the other type of text in which in all the data found, the failure in English -Indonesian text translation is 161 while in Indonesian-English text translation is 139 On the other hand, this study also revealed that the factors of the students ${ }^{\text {ee }}$ pragmatic failure that happened in their translation performance were coming from both the pragmatic transfer which influenced by either their native, source language or their understanding and lack of linguistic proficiency.
\end{abstract}

Published: (December, 2020)

Keywords: idiom, pragmatic failure, translation

\section{INTRODUCTION}

One of the main difficulties faced in translation is the pragmatic aspect of language. It is because as mentioned in Hickey (1998) that in translation there is a misleading transfer, not only in the language but also in the context. Therefore, to achieve an accurate and acceptable translation, pragmatic skills are needed. Pragmatic skill or pragmatic competence is the ability of someone as the hearer to understand the message implied by the speaker. Pragmatic competence is significant so that hearer comprehends what speakers say contextually (Cruz, 2018). Being able to understand the intention of what people say is one of the aspects that make the communication run as it is supposed to be. In contrast with pragmatic competence which is mentioned previously, the inability to understand the message implied in communication is what is called pragmatic failure. Lu (2019) mentioned that pragmatic inappropriateness as a pragmatic failure in line with the idea proposed by Thomas (1983). Thomas (1983) proposed the idea that pragmatic failure is the inability to understand what is meant by what is said. Based on the definition, there are two types of pragmatic failure; pragma linguistic failure and socio-pragmatic failure. Pragma-linguistic failure linked the linguistics matters which are mostly due to the lack of linguistic knowledge of the certain language that differs from Pragma-linguistic failure. Meanwhile, socio-pragmatic failure is linked to the inability to consider the social context of someone e idea which might happen due to cultural differences and limited knowledge of certain social aspects.

Several studies regarding pragmatic failure have been conducted. Al-Saidi \& Rashid (2015) analyzed pragmatic failure through the translation of published work both in English to Arabic and vice versa and the result of this study showed that non-natives generally do not consider the socio-pragmatic aspect when translating which led them to commit pragmatic failure. While Al-furaiji (2017) analyzed pragmatic failure through students' translation of political proverb done by Iraqi EFL students and the result showed that generally, the chosen participants failed to attain the duties in interpreting the given proverbs and it assumed that pragmatic failure raised in Iraqi EFL students" interpretation due to lack of pragmatic knowledge and linguistic inability. In 
addition, Natrio (2018) analyzed pragmatic failure through the translation of a proverb done by Indonesian EFL students and the result showed that the translation of the Indonesian proverb not acceptable in the target language considering how the cultural aspect is not transferred properly.

Considering those previous studies mentioned earlier, the researchers found a noticeable point as a consideration to do further research regarding the topic discussed. The gaps can be seen in the data of the analysis and the method of the analysis. Researchers conducted a study on pragmatic failure performed by Indonesian EFL students in translating the idioms. This is done by considering that translating idioms is difficult especially for those who are not aware of the cultural difference between the source language and the target language (Adelnia and Dastjerdi, 2011). In other words, the conversation will be more successful if people involved understand the idiom given (Adelina and Suprayogi, 2020). This research aims to investigate the possibilities of pragmatic failure done by Indonesian EFL students through their translation toward the idioms.

\section{LITERATURE REVIEW}

\section{Pragmatic Failure Types}

The inability to understand the message implied in communication is what is meant by pragmatic Failure. Those who do not have a good sense of pragmatic competence in communication considered as a person who pragmatically failed in grabbing the idea that arises in the communication where they are around. Thomas (1983) proposed this idea by mentioned that "Pragmatic Failure is the inability to understand what is meant by what is said". Riley (1989) as cited in Yusifova (2018) used another term that in line with this idea stated that pragmatic error is the inappropriate use of foreign social rules and behavior in one's culture by non-native users of the language. Thomas (1983) has composed types of pragmatic failure in her research journal i.e. pragma linguistic failure and socio-pragmatic failure.

\section{Pragma-linguistic Failure}

Pragma-linguistic failure is linked to linguistics matters. This failure happened when the hearer catches the speech acts strategy that is given by the speaker inappropriately, Thomas (1983). Pragma-linguistic failure usually happened when the linguistic structure of certain language produce by the non-native speaker is different from what has been set by the native one which makes the conversation sounds odd. The following is an example of Pragma-linguistic Failure:

A: Is it a good restaurant?

$B$ : of course

The conversation above occurs between Russian and native English. Linguistically, to answer that question should be answered with yes, it is as it is in the English context. Even though in Russian, konesnol, of course, used more often than $d a / y e s$, answering the question by using of course consider impolite in this context.

Differ from pragma-linguistic failure, socio-pragmatic failure linked to social context. This happened due to the differences from one culture to another met in the communication (Thomas, 1983). The topic in communication, when it considers social aspect often results from pragmatic failure due to the differences in the culture. One topic may be considered odd or unacceptable to one party while to the other one is simply a normal thing to discuss. The following is the example of Socio-pragmatic Failure

A: you look so thin; how much do you weigh?

B: umm, well...

The discussion above occurs between Korean and Native English. Considering the Korean aspect, asking about weight is pretty taboo, and being in that situation causes an awkward atmosphere. As the native one probably did not know about it make the discussion did go well.

\section{Pragmatic Failure Factors}

Things happened with reason and committed pragmatic failure as well. Pragmatic failure usually happened because of the factors namely lack of linguistic competence and cultural differences. A deeper explanation was given by Thomas (1983), pragma-linguistic failure may arise from two identifiable sources: teaching-induced errors and pragma-linguistic transfer while socio-pragmatic failure is caused by several factors such as the size of imposition, taboos, and cross-culturally different assessments of relative power or social distance. Another explanation given by Wulandari et al (2018) found that pragmatic failure is caused by five reasons, "namely failure in understanding others' intentions, failures in understanding others' state, denials to the reality, trauma, and failures in understanding a situation. Thus, the researcher decided after several considerations to use the theory given by Muir 
et al (2011). This is done because several factors given by those researchers Thomas (2013) and Wulandari et al (2018) could be simplified into the factors below.

\section{Pragmatic Transfer}

The phenomenon of pragmatic failure may arise from the fact that the interference of the target language is playing a big role in communication. Thus, the limited knowledge of the identity of the target language may be the bigger influence on the pragmatic transfer in the communication that affects the non-native speakers' performance negatively. Moreover, it is found many times that non-native speakers often are influenced by the identity of their first language while having communication in the target language. Muir et al (2011) stated that in their performance, non-native often influence by the cultural norms of their mother language. Kuswoyo (2014) supported the argument stated that non-native speaker often experiences challenges in learning a new language because their habit influenced much on their performance.

\section{Linguistic Proficiency}

Wolfon (1989) as cited in Muir et al (2011) argues that pragmatic failure not only exists because of the pragmatic transfer but also the limited linguistic knowledge of the target language. It often happens to non-native that they produce native-like languages which linguistically inappropriate that happen because of low linguistic proficiency. While investigating apologies, Wolfon (1989) as cited in Muir et al (2011) founds that non-native speakers often express an inappropriate degree of regret because their proficiency was inadequate.

\section{METHOD}

This study is limited to find out the types of pragmatic failure and the factor(s) causing pragmatic failure on students' translating performance. This study implements a descriptive qualitative method because the collected data are presented in a structured or written way according to Gulö \&Rahmawelly (2019). This method is chosen because the researchers can collect the data in several ways; interviews, observation, and focus group discussion, and the data will not be presented in a statistical way (Kuswoyo and Audina, 2020). The participants of this study are 20 EFL students coming from one of the private universities in Indonesia and English Literature in the third year who have already taken or are taking the second stage of translation class. In conducting this research, the data of this research is students' translation of idiom in the form of sentence and students' interview result. Both are needed to get a more accurate result of students' real condition while facing the difficulties in translating the text given. As the subject of this research, the respondents are asked to translate texts from English to Indonesian and/or vice versa. In this research, the texts given are texts which contain idiom in the form of short dialogue adapted from several sources found in related sources in 20 short dialogues. After having the instrument, to collect the data, the writers asked the respondents to translate the texts. Then, right after the translation results are received, the writers checked the translation and does the interview after. After gathering the result of both translation and interview, the writers took note of the important things that could be studied based on the theory used. After collecting the data, the researcher analyzed the data in several steps. First, the researchers separate the data depending on the step to get the data because the data are used to answer a different research question. Then, for the first research question, the data classified into two types of pragmatic failure. Next, for the second research question, the data are categorized into several factors. The result of this study will not make any generalization to the Indonesian EFL students because this study is done on a small scale.

\section{FINDINGS AND DISCUSSION}

The first part of this chapter discussing the finding of the first research question which is what is a pragmatic failure and its types found on the chosen EFL students' translation performance. Then, the second part of this chapter discusses the finding of the second research question in which what are the factors that are caused pragmatic failure found on the chosen EFL students. The data and explanation are discussed below.

\section{Types of Pragmatic Failure}

Considering the result of the translation given to the respondents, nearly all of the translation given by the respondents failed both in either pragma-linguistic failure or socio-pragmatic failure. After analyzing the texts, it is found that the failure in English-Indonesian translation is higher in number compared to Indonesia- English translation. Either pragma-linguistic failure or socio-pragmatic failures are found in English Indonesian translation is higher in number than those in Indonesian-English translation. The detail of several failures can be seen in the following table below.

Table 1. Pragmatic Failure found in the chosen EFL students translation performance

\begin{tabular}{|l|l|l|}
\hline Short Dialogue Text & Pragma-linguistic Failure & Socio-pragmatic Failure \\
\hline
\end{tabular}




\begin{tabular}{|c|c|c|}
\hline English-Indonesian & 71 & 90 \\
\hline Indonesian-English & 52 & 87 \\
\hline Total Failure & $\mathbf{1 2 3}$ & $\mathbf{1 7 7}$ \\
\hline
\end{tabular}

\section{Types of Pragmatic Failure in English-Indonesian Translation}

Several analyses have been done to the translation result in English-Indonesian idiom short dialogue texts, and it shows that types of pragmatic failure both pragma-linguistic failure and socio-pragmatic failure exist in EnglishIndonesian idiom short dialogue texts translation result. The detail can be seen in the following table below.

Table 2. Detail of Pragmatic Failure found in English-Indonesian Translation

\begin{tabular}{|c|c|c|}
\hline Idiom Text & Pragma-linguistic Failure & Socio-pragmatic Failure \\
\hline Leave no stone unturned & 3 & 13 \\
\hline Bookworm. & 7 & 1 \\
\hline Let sleeping dogs lie. & 4 & 14 \\
\hline Spill the tea & 11 & 9 \\
\hline In a blink of an eye & 11 & 11 \\
\hline My cup of tea & 5 & 7 \\
\hline It"s a piece of cake & 10 & 6 \\
\hline Cut me dead & 8 & 14 \\
\hline Beating about the bush & 5 & 4 \\
\hline Hit the hay now & 7 & 11 \\
\hline Total Failure & $\mathbf{7 1}$ & $\mathbf{9 0}$ \\
\hline
\end{tabular}

\section{Pragma-Linguistic Failure in English-Indonesian Translation}

There are several types of failure found in English -Indonesian idiom text translation. First, it happened due to the text did not transfer to the target language. Second, it happened because of the unacceptable structure given by the respondents when it comes to the target language structural form and last is because of the word choices. The discussion of Pragma-linguistic failure found in English -Indonesian idiom text translation happened in several ways can be seen as followed.

\section{Maya: I'd bring my sister but I don't think I can stop her from reading even for new game. She's bookworm. (Datum 2) \\ Maya: Ok saya akan ajak kakak saya tapi saya rasa saya tidak bsa menghentikan nya untuk berhenti membaca, karena dia kutu butu sis.}

The translation above is considered as pragma-linguistic failure. This is because the transfer given by the translator is considered linguistically inaccurate in the target language. In the target language, the word sis has its meaning which is commonly known as partner we are talking to but it does not accept linguistically in the target language because such a word is adapted from English and applied in casual conversation. The point is that, from the transfer given, it clearly shows that the translator failed to transfer the text given to the target language. The occurrence of the word sis is confusing considering the target language.

\section{Socio-Pragmatic Failure in English-Indonesian Translation}

Compared to the pragma-linguistic failure, the identification of socio-pragmatic failure found in EnglishIndonesian Idiom text translation is easier to be identified because as long as the intention of the source language did not transfer to the target language then it becomes one. Even though it easier to identify socio-pragmatic failure, there are several types of failure found in English -Indonesian idiom text translation. First, it happened due to the whole meaning of the text given did not transfer to the target language correctly. Second, it happened because the idiom given did not transfer to the target language correctly so it makes the translation less accurate. The discussion of Pragma-linguistic failure found in English -Indonesian idiom text translation happened in several ways can be seen as followed.

May: I'll leave no stone unturned. (Datum 11)

May: aku tidak akan meninggalkan batu terlewat

The translation above is considered as socio-pragmatic failure. This due to the fact that the message transferred to the target language is unacceptable. In the source language, the idiomleave no stone unturned has 
its meaning in which the speaker in the dialogue will find the gemstone and give it back to her partner while in the translation, the translator transfers the idea by giving the literal meaning in each word which changes the meaning that the speaker will not leave the unrecognizable stone. The transfer in the target language is not understandable. This translates failed pragmatically because it is not only inaccurate but also unacceptable.

\section{Types of Pragmatic Failure in Indonesian-English Translation}

The translation above is considered a socio-pragmatic failure. This due to the fact that the message transferred to the target language is unacceptable. In the source language, the idiom leave no stone unturned have its meaning in which the speaker in the dialogue will find the gemstone and give it back to her partner while in the translation, the translator transfer the idea by giving the literal meaning in each word which changes the meaning that the speaker will not leave the unrecognizable stone. The transfer in the target language is not understandable. This translates failed pragmatically because it is not only inaccurate but also unacceptable.

Table 3. Detail of Pragmatic Failure found in Indonesian - English Translation

\begin{tabular}{|c|c|c|}
\hline Idiom Text & Pragma-linguistic Failure & Socio-pragmatic Failure \\
\hline Tidak akan tinggal diam & 4 & 15 \\
\hline Mahluk halus & 4 & 2 \\
\hline Sepert tersambar petir & 2 & 19 \\
\hline Keras kepala & 9 & 2 \\
\hline Jatuh cinta & 7 & 8 \\
\hline Kantong Kering & 5 & 14 \\
\hline Banting harga & 6 & 10 \\
\hline Banting tulang & 3 & 4 \\
\hline ikut campur & 3 & $\mathbf{8 7}$ \\
\hline Banting setir & 9 & \\
\hline Total Failure & $\mathbf{5}$ & \\
\hline
\end{tabular}

\section{Pragma-Linguistic Failure in Indonesian-English Translation}

There are several types of failure found in Indonesian - English idiom text translation. First, it happened due to the text did not transfer to the target language. Second, it happened because of the unacceptable structure given by the respondents when it comes to the target language structural form. The discussion of Pragmalinguistic failure found in Indonesian-English idiom text translation happened in several ways can be seen as followed.

Rika: coba saja, aku tidak akan tidak tinggal diam. (Datum 21) Rika: Try me, I'm will not keep silent

The translation above is considered as pragma-linguistic failure. This is because the transfer given by the translator is considered linguistically inaccurate in the target language. In the target language, the word I'm in the translation is not acceptable and can be replaced by the words $I$. The translator should omit the " $\mathrm{m}$ " to translate is acceptable structurally. Then, the transfer can be made in to "try me, I will not keep silent". The transfer is unacceptable in the target language because it does not fulfill the structure form of the target language. On the other hand, it also is confusing to the reader because it is not clear either the speaker is doing the action or will doing the action.

\section{Socio-Pragmatic Failure in Indonesian-English Translation}

Compared to the pragma-linguistic failure, the identification of socio-pragmatic failure found in Indonesian - English Idiom text translation is easier to be identified because as long as the intention of the source language did not transfer to the target language then it becomes one. Even though it easier to identify socio-pragmatic failure, there are several types of failure found in Indonesian - English idiom text translation. First, it happened due to the whole meaning of the text given did not transfer to the target language correctly. Second, it happened because the idiom given did not transfer to the target language correctly so it makes the translation less accurate. The discussion of Pragma-linguistic failure found in Indonesian. Here is an example.

\section{A: lebih baik aku diomeli sepanjang malam daripada harus melihat mahluk halus disini, kalian kan tahu ini hutan. (Datum 32)}

A: It better than getting together with the insects. 
The translation above is considered a socio-pragmatic failure. This because the message transferred to the target language is inaccurate. In the source language, the idiom mahluk halus has its meaning in which the speaker in the dialogue feels that he should be nagged by his parents rather than seeing spirits because he and his partner are in the forest while in the translation, the translator transfers the idea by changing the meaning of the source language that the speaker feels that it is better for him to be nagged by his parents rather than being together with insects. The transfer in the target language is acceptable but inaccurate because it missed the intention of the source language.

\section{Factors of Pragmatic Failure}

After some consideration which coming from the researcher's observation, this research revealed several factors that caused the failure performed by the respondents in which the failure happens both because of the pragmatic transfer and lack of linguistic proficiency. The failures also mentioned considering the result of the translation given by the respondents and the interview done to them. Nearly all of the students who performed pragmatic failure admit that factors to their failure are those already mentioned previously and it also can be seen in their performance. A deeper explanation can be seen below.

\section{Factors of Pragmatic Failure in English-Indonesian Translation}

Several failures are found In the English-Indonesian Translation result given by the respondents which are caused by several factors, the pragmatic transfer and lack of linguistic proficiency. Both of which are discussed in a deeper explanation can be seen below.

\section{Pragmatic Transfer}

The first factor that is considered as the cause of why the respondents performed pragmatic failure and failed to translate the short dialogue is because they failed to grab the intention in the source language. Somehow the respondents translated the text given in a less accurate translation because even though most of them successfully translate the idiom, somehow the meaning as a whole text is incorrectly transferred. This is also supported by the statement given in the interview by the respondents which she confirmed that what makes her often performed pragmatic failure in communication especially when it deals with English in which she is not a native to it is because she is not familiar with the topic discussed in the source language while she uses English as the language she speaks at the time. This factor is also supported by the fact that in the interview, some of the respondents lost at the question given to them. Instead of answering the reason why they performed pragmatic failure in communication, they answer it by explaining what is pragmatic or the causes of pragmatic failure in general but do not mention the reason why it happens to them.

\section{Linguistic Proficiency}

Another factor that caused a pragmatic failure in English - Indonesian idiom translation is the lack of linguistic knowledge in Indonesian when it comes to their first language. Even though they are the native Indonesian language, they also performed failure in terms of linguistic failure because some of the translations given in Indonesian are not acceptable considering the language standard of Indonesian. Some students giving the translation based on their linguistic knowledge which somehow, they did not aware that the word choices or the structure they performed are not accurate resulting them make such an acceptable translation to the target language but considered less accurate because it does not fulfill the standard language of Indonesian.

\section{Factors of Pragmatic Failure in Indonesian-English Translation}

Similar to the English-Indonesian Translation result, several failures which are caused by several factors were also found in Indonesian-English, the pragmatic transfer and lack of linguistic proficiency. Both of which are discussed in a deeper explanation can be seen below.

\section{Pragmatic Transfer}

The first noticeable factor in Indonesian-English translation pragmatic failure happens because the respondents often influenced by their first language rule while performed the translation. This can be seen in the students' translation result that is displayed before which clearly shows that the translation, they performed is either unacceptable, inaccurate, or less accurate considering the target language rules. In some cases, the failure also happened because they translate the text, especially the idiom has given by giving literal translation to each word that constructs the idiom in which somehow translates seems strange. After all, it does not make sense considering the whole meaning of the text given. 


\section{Linguistic Proficiency}

The second factor that is noticeable which considered as the caused why the respondents performed pragmatic failure and failed to translate the text given which is short dialogue text which contains idiom in it is because they mostly lack linguistic proficiency when it comes to English. While in the translation to English, the noticeable failure happened can be seen in how the translator structurally failed to transfer the message from the target language. Somehow, the text is given also translated to the target language by adapting the source language rules in which in some texts are acceptable but most are not because it translates seems strange in the perspective of English.

\section{CONCLUSION}

This study has shown that nearly all Indonesian EFL students as the respondents of this study performed pragmatic failure in their translation. Thus, through this study, the writers highly suggested that Indonesian EFL should improve their ability especially in English because when it comes to using a foreign language, it is not only about being able to use such language but it also requires the ability to understand how to use such language in a certain way which in this study that the respondents, Indonesian EFL students are lack of. The skills to grab the intention of one language and transfer it to the target language with the incorrect and acceptable structure are helpful to those who use or learn a foreign language. Those skills can be practiced anywhere, anytime. It is also suggested to those who are interested in the topic discussed in this research to study further to the field that this study is limited on which can be coming from other theory, subject or anything else that can develop the discussion in this field, pragmatics.

\section{REFERENCES}

Adelina, C \& Suprayogi. (2020). Contrastive analysis of English and Indonesian idioms of human body. Linguistic and Literature Journal, 1(1), 21-26.

Adelnia, A. \& Dastjerdi, H. M. (2011). Translation of idiom: A hard task for the translator. Theory and Practice in Language Studies, 1(7), 879-883.

Al-Furaiji, A. S. ( 2017). Pragma linguistic failure of Iraqi EFL fourth-year university students in interpreting some political proverbs. Journal of Social Science, 3(2), 127-138.

Al-Saidi, A. H. S \& Rashid, S. Md. (2015). Investigating socio-pragmatic failure in cross-cultural translation: a theoretical perspective. Arab World English Journal Special Issue on Translation, (4). 113-126.

Cruz, M. P. (2018). Pragmatic Competence Injustice. Social Epistemology.

Gulö, Ingatan \& Rahmawelly, T, V. (2018). An analysis of omission in students' English writings. Teknosastik: Jurnal Bahasa dan Sastra, 16(2), 55-59.

Hickey, L. (1998). The pragmatics of translation. Philadelphia: Multilingual Matters Ltd.

Kuswoyo, H \& Audina, A, Y. (2020). Consecutive interpreting strategies on a court setting: a study of English into Indonesia interpretation. Teknosastik. Jurnal Bahasa dan Sastra, 18(2), 90-102.

Kuswoyo, H. (2014). Declarative sentence pattern in "Laskar Pelangi" and "The Rainbow Troops": A translation study of Indonesian to English. Advances in Language and Literary Studies, 5(1), 117-121.

Lu, L. (2019). Pragmatic failure in interpretation and the development of students' pragmatic competence in interpreting. English Language Teaching, 12(3). 37-45.

Muir, P. Y. \& Xu, Z. (2011). Exploring pragmatic failure into the writing of young EFL learners: A critical analysis. English Language Teaching, 4(4). 254-261.

Natrio, Y. (2018). Pragmatic failure in interpreting some proverbs found in SMAN 1 Lubuk Alung. Jurnal Arbiter, 5(1), 42-47. 
Riley, P. (1989). Well Don't Blame Me!- On the Interpretation of pragmatic errors in W. Oleksy. Contrastive Pragmatic. Amsterdam: John Benjamin Publishing Company.

Thomas, J. 1983. Cross-cultural pragmatic failure. Applied Linguistics, 4(2), 91-112.

Thomas, J. 2013. Meaning in Interaction: An Introduction to Pragmatics. New York: Routledge.

Wulandari, A., Hapsari, B. S., \& Bram, B. 2018. Communication failures in Netflix drama series "13 reasons why": a pragmatic analysis. International Journal of Humanity Studies, 1(2), 264-272.

Yusifova, P. 2018. Three layers of pragmatic failure across languages and cultures. International Journal of English Linguistics, 8(6), 256-2 